\title{
Measurement and simulation of crop photosynthesis of cucumber (Cucumis sativus L.) in greenhouses
}

\author{
E. M. Nederhoff ${ }^{1}$, J. G. Gijzen ${ }^{2}$ and J. Vegter ${ }^{1}$ \\ ${ }^{1}$ Glasshouse Crops Research Station, P.O. Box 8, NL 2670 AA Naaldwijk, Ne- \\ therlands \\ ${ }^{2}$ Department of Theoretical Production Ecology, Wageningen Agricultural Uni- \\ versity, seconded to the Centre for Agrobiological Research, P.O. Box 14, NL \\ 6700 AA Wageningen, Netherlands
}

Received 15 January 1988; accepted 5 April 1988

Key words: Cucumis sativus $\mathrm{L}$., cucumber, photosynthesis, greenhouse ventilation, carbon dioxide, nitrous oxide, simulation

\begin{abstract}
Short-term photosynthesis measurements were performed in a cucumber crop ( $\mathrm{Cu}$ cumis sativus $\mathbf{L}$.) in three experimental greenhouse compartments. The greenhouse was used as a measuring cuvette for the whole canopy. The calculated carbon dioxide balance of the greenhouse was based on measurements of the carbon dioxide concentrations inside and outdoors, combined with on-line measurement of the ventilation rate.

The method is described and results of three characteristic days are presented. A positive correlation was found between photosynthesis rate and both radiation and $\mathrm{CO}_{2}$ concentration. Measured environmental conditions were given as input data into a simulation model. The simulated and measured rates of photosynthesis generally showed a close similarity.
\end{abstract}

\section{Introduction}

In horticulture, as in other agricultural sectors, crop simulation models are being developed for several purposes, e.g. scientific analysis, production planning or crop management. In greenhouse horticulture, where crops are grown in an artificial environment, an additional purpose for models is to employ them for optimal, automatic climate control (Challa, 1985). A model for this application should meet special requirements, e.g. the time scale for calculations must be small (order of magnitude: some minutes). In the Netherlands a project group is working on a greenhouse climate control system consisting of a physiological, a physical and an economic model, combined with an optimization algorithm. As a first result an optimiza- 
tion program for $\mathrm{CO}_{2}$ control has been developed (Challa \& Schapendonk, 1986; Nederhoff, 1988).

An essential part of the work is the validation of the physiological models for several crops. This should be done on different levels: light interception, photosynthesis, dry matter production and distribution, and crop growth and production. Ideally, validation should be performed on a fullgrown crop in a relatively large greenhouse. Photosynthesis measurements on such a scale are rare (Dayan et al., 1985). More often the photosynthesis is measured on one leaf (e.g. McPherson et al., 1983; Ho et al., 1984), on a single plant (e.g. Gaastra, 1959; Nilwik, 1980; Lakso et al., 1984) or on several plants (Schapendonk \& Brouwer, 1985) in a measuring cuvette. In these small-scale measurements, the conditions differ from those in greenhouses, especially with respect to light interception (Nederhoff, 1983). Such measurements in cuvettes are therefore not suitable for validation of crop models meant for practical use.

Lake (1966) proposed photosynthesis measurements using the entire greenhouse as a measuring cuvette for a whole plant stand. This method is based on determining the carbon dioxide balance of the greenhouse air. At the same time the ventilation rate of the greenhouse should be measured (on-line) with a tracer gas, for which nitrous oxide $\left(\mathrm{N}_{2} \mathrm{O}\right)$ can be used. This method with nitrous oxide as tracer gas was applied earlier for photosynthesis measurements (Hand \& Bowman, 1969) and for ventilation measurements (Goedhart et al., 1984). Dayan et al. (1985) applied this method for photosynthesis measurements in relatively large-size greenhouses. Matthews et al. (1987) described a $\mathrm{CO}_{2}$ control system, based on off-line ventilation measurements with $\mathrm{N}_{2} \mathrm{O}$.

In this paper, model validation on the level of crop photosynthesis is reported. The method of Lake (1966) is employed to measure photosynthesis of a cucumber crop in experimental greenhouses. The environmental data that were acquired in the experiment were given as input data into the simulation model. The photosynthesis rates simulated on the basis of these data were compared with the measured photosynthesis.

\section{Materials and methods}

\section{Greenhouse}

The measurements were done in three compartments $(9.6 \mathrm{~m} \times 6 \mathrm{~m}$; average height $2.95 \mathrm{~m}$ ), of a Venlo-type greenhouse complex. Ventilation windows, situated in the roof, were opened when necessary for cooling, also during the measurements. The walls between compartments were made as air-tight as possible with silicone paste, in order to avoid uncontrolled and unmeasurable inflow of $\mathrm{CO}_{2}$ and $\mathrm{N}_{2} \mathrm{O}$ from adjacent compartments.

The ventilation rate of the compartments was determined earlier with tracer gas measurements (Nederhoff et al., 1985) and appeared to be proportional with wind velocity and window aperture (up to $20 \%$ ):

$$
S=0.073 \times u \times(w+l)
$$


where: $S=$ air exchange rate (volume per volume per hour) $\left(\mathrm{h}^{-1}\right)$

$u=$ wind velocity (average in the time interval) $\left(\mathrm{m} \mathrm{s}^{-1}\right)$

$w=$ window aperture (relative: $100 \%=0.66 \mathrm{~m}$ gap) $(\%)$

$l=1.33$, a constant describing the leak of the greenhouse $(\%)$.

In principle it is possible to use Equation 1 for the estimation of ventilation and photosynthesis. This method is followed by Matthews et al. (1987). However, online measurement of the ventilation is preferred, because then any deviation or delay in air exchange rate is detected directly and the photosynthesis is calculated more accurately.

\section{Crop}

A cucumber crop (Cucumis sativus L. cv. Corona), was planted on rockwool on 13 August 1987. Plant density was 1.92 plants per $\mathrm{m}^{2}$. The photosynthesis measurements were started on 25 August, 12 days after planting, and ended on 20 October, when the LAI was 3.4, the dry weight of leaves was about $56 \mathrm{~g}$ and of stems about 58 g per plant. Every two or three weeks, five plants were taken from an adjacent, identical greenhouse compartment. From these plants the dry weights of leaves and stems, the number of leaves and the leaf area were determined.

Cucumber fruits were harvested twice a week, the first harvest was on $10 \mathrm{Sep}$ tember and the last on 22 October. At each harvest the fruits were classified, counted and weighed. Sometimes, pruning of leaves was applied. A summary of the plant parameters is given in Table 1.

Table 1. Plant parameters of a cucumber crop on 5 dates in 1987 during the photosynthesis experiment. Data are given per plant, except leaf area index $\left(\mathrm{m}^{2}\right.$ leaf per $\mathrm{m}^{2}$ cultivated greenhouse area) and dry matter content (\%).

\begin{tabular}{|c|c|c|c|c|c|}
\hline Parameter & 20 Aug. & 03 Sep. & 19 Sep. & 10 Oct. & $22 \mathrm{Oct}$ \\
\hline Leaf area $\left(\mathrm{m}^{2}\right)$ & 0.2 & 1.5 & 1.8 & 1.6 & 1.8 \\
\hline Leaf area index & 0.3 & 3.0 & 3.5 & 3.1 & 3.4 \\
\hline Fresh weight of leaves (g) & 35.2 & 396.7 & 459.3 & 366.3 & 423.0 \\
\hline Fresh weight of stems (g) & 54.5 & 511.4 & 703.6 & 784.1 & 1014.0 \\
\hline Dry weight of leaves $(\mathrm{g})$ & 4.6 & 41.6 & 47.5 & 42.3 & 55.6 \\
\hline Dry weight of stems $(\mathrm{g})$ & 2.7 & 25.5 & 32.9 & 41.7 & 57.6 \\
\hline Dry matter content of leaves $(\%)$ & 13.1 & 10.5 & 10.3 & 11.5 & 13.3 \\
\hline Dry matter content of stems (\%) & 5.0 & 5.0 & 4.7 & 5.3 & 5.7 \\
\hline \multicolumn{6}{|l|}{ Cumulative weights } \\
\hline $\begin{array}{l}\text { Fresh weight of } \\
\text { harvested fruits (g) }\end{array}$ & - & _- & 2109 & 5244 & 6625 \\
\hline Dry weight of harvested fruits ${ }^{1}(\mathrm{~g})$ & - & - & 57 & 142 & 179 \\
\hline $\begin{array}{l}\text { Estimated dry weight of leaves } \\
\text { removed by pruning }(\mathrm{g})\end{array}$ & - & - & 5.5 & 7.6 & 7.6 \\
\hline $\begin{array}{l}\text { Estimated dry matter } \\
\text { production }{ }^{2}(\mathrm{~g})\end{array}$ & 7.3 & 74.4 & 158 & 256 & 321 \\
\hline
\end{tabular}




\section{Environmental factors}

The average weather conditions in the Netherlands at the beginning and the end of the experiment respectively, were:

- average minimum temperature: 14.1 and $8.5^{\circ} \mathrm{C}$;

- average maximum temperature: 19.6 and $15.0^{\circ} \mathrm{C}$;

- daily sum of global radiation: 16.0 and $7.2 \mathrm{MJ} \cdot \mathrm{m}^{-2}$;

- daylength: 14.3 and $10.0 \mathrm{~h}$.

The environmental conditions maintained in the greenhouse were comparable to those in commercial greenhouse culture. Setpoint for heating was $25^{\circ} \mathrm{C}$ by day and $20^{\circ} \mathrm{C}$ at night. From the beginning of October a minimum heating-pipe temperature of $50{ }^{\circ} \mathrm{C}$ and a small minimum ventilation were maintained in order to decrease relative humidity and consequently the risk of fungal diseases.

Relevant environmental factors were measured and recorded, to be used as input data for the photosynthesis model. The recorded factors were: $\mathrm{CO}_{2}$ concentrations as measured by the $\mathrm{CO}_{2}$ analyser, global radiation measured outside (diffuse and total), Photosynthetically Active Radiation (PAR) measured inside and outside the greenhouse, and temperature and humidity of the greenhouse air. The factors were measured on a one-minute basis, but were averaged over the calculation cycle (about 11 minutes, see below).

\section{Determination of photosynthesis}

In this work the photosynthesis rate of a greenhouse cucumber crop is determined by measuring the carbon dioxide mass balance of the greenhouse air. The greenhouse was an open system because the roof was not completely air-tight and the compartments were ventilated when necessary for temperature control. The general balance equation for $\mathrm{CO}_{2}$ is:

$$
\mathrm{d} C_{\mathrm{g}}(t) / \mathrm{d} t=(G+I-P-L) /(h \times \varrho)
$$

where:

$t=$ time $(\mathrm{h})$

$C_{\mathrm{g}}(t)=\mathrm{CO}_{2}$ concentration in the greenhouse at time $t\left(\mathrm{ppm}=\mathrm{ml} \mathrm{m}^{-3}\right)$

$G=$ release of $\mathrm{CO}_{2}$ from the ground $\left(\mathrm{g} \mathrm{m}^{-2} \mathrm{~h}^{-1}\right)$

$I=$ suppletion (injection) of $\mathrm{CO}_{2}\left(\mathrm{~g} \mathrm{~m}^{-2} \mathrm{~h}^{-1}\right)$

$P=$ photosynthesis rate $\left(\mathrm{g} \mathrm{m}^{-2} \mathrm{~h}^{-1}\right)$

$L=$ loss of $\mathrm{CO}_{2}$ by ventilation (including leak) $\left(\mathrm{g} \mathrm{m}^{-2} \mathrm{~h}^{-1}\right)$

$h=$ average height of the greenhouse $(\mathrm{m})$

$\varrho=$ gas density of $\mathrm{CO}_{2}$ at $20^{\circ} \mathrm{C}$ and $1013 \mathrm{mb}, 1.83 \times 10^{-3}\left(\mathrm{~g} \mathrm{ml}^{-1}\right)$.

The supply of $\mathrm{CO}_{2}(I)$ was off during the measurements and the release of $\mathrm{CO}_{2}$ from the soil $(G)$ was zero, since the soil was covered with concrete. Therefore Equation 2 can be rewritten as:

$$
P=-\mathrm{d} C_{\mathrm{g}}(t) / \mathrm{d} t \times \varrho \times h-L
$$


The rate of decay of the $\mathrm{CO}_{2}$ concentration in the greenhouse air, $\mathrm{d} C_{\mathrm{g}} /(t) / \mathrm{d} t$, was determined by frequent measurements of the $\mathrm{CO}_{2}$ concentration in each compartment. The loss of $\mathrm{CO}_{2}$ by leak and ventilation, $\mathrm{L}$, was calculated from the ventilation rate $S$, as follows:

$$
\begin{aligned}
& L=S \times h \times \varrho \times \int C^{\prime}(t) \mathrm{d} t \\
& C^{\prime}(t)=C_{\mathrm{g}}(t)-C_{\mathrm{a}}(t)
\end{aligned}
$$

where:

$C^{\prime}(t)=\mathrm{CO}_{2}$ difference between inside and outside air (ppm)

$C_{\mathrm{a}}(t)=\mathrm{CO}_{2}$ concentration of the ambient air $(\mathrm{ppm})$.

For relatively short periods (some minutes) as were used in these experiments, the integral $\int C^{\prime}(t) \mathrm{d} t$ can be replaced by the average value $C^{\prime}(t)$ over the period. Equation 4a can be written as:

$$
L=S \times h \times \varrho \times C^{\prime}(t)
$$

$S$ was determined accurately with the tracer gas nitrous oxide $\left(\mathrm{N}_{2} \mathrm{O}\right)$. This gas was injected to a level of about 300 ppm. Then the $\mathrm{N}_{2} \mathrm{O}$ supply was stopped and after a short waiting time to allow mixing of the gases in the air, the measurement was started. This method, known as the decay rate method, was described by Goedhart et al. (1984). In this experiment the time and frequency for the $\mathrm{N}_{2} \mathrm{O}$ concentration measurements were the same as those for $\mathrm{CO}_{2}$ (see below). The ventilation rate $S$ was calculated according to:

$$
S=\mathrm{d}(\ln (N(t)) / \mathrm{d} t
$$

where:

$N(\mathrm{t})=\mathrm{N}_{2} \mathrm{O}$ concentration at time $t$

(ppm).

The $\mathrm{CO}_{2}$ concentration of the ambient air, necessary in Eq. 4, was measured in every measuring cycle. Because in one measuring period (some hours) the change in the ambient $\mathrm{CO}_{2}$ concentration is rather small (some ppm), one average ambient $\mathrm{CO}_{2}$ value over the measuring period was used.

\section{Instruments and other equipment}

The equipment consisted of two infra-red gas analysers (Hartmann \& Braun, URAS $3 \mathrm{G}$ ): one for $\mathrm{CO}_{2}$ and one for $\mathrm{N}_{2} \mathrm{O}$, a microcomputer and, per greenhouse compartment, a gas sampling system and a gas supply and gas distribution system and fan. The system for injection and distribution of the gases consisted of a network of plastic tubes (diameter $0.04 \mathrm{~m}$ ), located on the ground with intervals of 3.2 $\mathrm{m}$. Carbon dioxide was obtained from a tank and nitrous oxide from pressure bottles. 
Gas was subsequently sampled in four objects: three greenhouse compartments and the outside environment. There was one central air pump and one carbon filter for the four objects. In each compartment a sampling system of $6 \mathrm{~mm}$ tubes with four inlets was used. While one compartment was sampled, the air in the three other sampling objects was drawn continuously by another pump, in order to maintain air movement in the sampling system.

The gas concentration measurements were controlled and recorded on tape by an Epson HX-20 microcomputer. The data were transferred to a VAX-750 computer, on which the photosynthesis calculations were performed. Relevant environmental factors (radiation intensities, air temperature etc.) were recorded using a MICRO-VAX system and also transferred to the VAX-750.

\section{Measuring and calculating cycles}

Measurements were done by day and night. The first measurement was on $25 \mathrm{Au}-$ gust and the last on 20 October. Mostly, a measurement lasted one to several hours, after which a new measurement was started, with a short delay of about 15 minutes. In this way, measurements were done on 36 days and 20 nights, together about 300 hours.

The measuring cycle depended on the relaxation time of the analysers, which was $30 \mathrm{~s}$, the number of sampling objects, which was four and the time-dependent variation in gas concentration. By day the measuring cycle was set on $208 \mathrm{~s}(4 \times 52)$. At night it was $688 \mathrm{~s}(4 \times 172)$, because then the rate of changes of gas concentrations was comparatively low.

The calculation cycle was different. In order to smooth out the variances caused by measuring errors, the photosynthesis calculations with Equations 3, 4 and 5 were applied on four data of the $\mathrm{CO}_{2}$ and $\mathrm{N}_{2} \mathrm{O}$ concentration, using a regression calculation. So the time interval for the calculation of photosynthesis (at daytime) was 624 $s(4 \times 208 \mathrm{~s})$. For the calculation of the respiration (at night) 2 data were used, making a calculation interval of $688 \mathrm{~s}$.

\section{Simulation model}

The photosynthesis model is based on the model SUCROS (Simple and Universal CROp growth Simulator, Spitters et al., 1988). The model calculates the net crop photosynthesis from gross photosynthesis, maintenance and growth respiration, as described by Gijzen \& ten Cate (1988). The model is an integration of physical models: one for the calculation of fluxes of direct and diffuse light into the greenhouse (Bot, 1983) and one for the calculation of the light distribution in the canopy, and a physiological model for leaf photosynthesis. For the light distribution the crop is assumed to be a horizontally homogeneous canopy.

The model for leaf photosynthesis was a summary model of the biochemical theory of leaf photosynthesis as described by Farquhar et al. (1980). The summary model is preferred because its two key parameters (the efficiency of light use at low light intensities and the rate of leaf photosynthesis at light saturation) can be compared 
with many other values already published (e.g. Acock et al., 1978; Ehleringer \& Pearcy, 1983). In the model, the values of both parameters are influenced by $\mathrm{CO}_{2}$ concentration and temperature.

The values of the main parameters and variables in the model were:

- azimuth of greenhouse: North-South;

- transmissivity of greenhouse cover for diffuse ${ }^{1}$ radiation: 0.63 ;

- leaf area index of crop: increasing with time, see Table 1;

- leaf angle distribution: horizontal;

- light use efficiency at low light intensity ${ }^{2}: 0.011 \mathrm{mg} \mathrm{CO}_{2} \mathrm{~J}^{-1}$

- gross photosynthesis rate at light saturation ${ }^{2}: 0.911 \mathrm{mg} \mathrm{CO}_{2} \mathrm{~m}^{-2}$ (leaf area) s ${ }^{-1}$

- rate of maintenance respiration of total crop: $0.5 \mathrm{~g} \mathrm{CO}_{2} \mathrm{~m}^{-2}$ (greenhouse area)

$\mathbf{h}^{-1}$. The maintenance respiration was derived from measurements at night. Then the plants released $\mathrm{CO}_{2}$ by both growth respiration and maintenance respiration. At the end of the night, the growth respiration was supposed to have declined to zero.

\section{Results}

From the large amount of data (36 measuring days in three compartments), three characteristic examples were chosen: from one compartment one day at the beginning, one at the middle and one at the end of the experiment were selected to illustrate the comparison between simulated and measured photosynthesis rates.

Fig. 1 shows the results of 26 August, two weeks after planting. In Fig. 1a the environmental conditions are plotted: global radiation outside (measured), PAR inside the greenhouse (calculated) and $\mathrm{CO}_{2}$ concentration of the greenhouse air. In Fig. $1 \mathrm{~b}$ the measured and simulated photosynthesis rates are plotted. 26 August was a partly cloudy day. Peak radiation (of about $700 \mathrm{~W} \mathrm{~m}^{-2}$ ) occurred between 12.30 and $14.30 \mathrm{~h}$. The temperature (not in the figures) was raised from $22{ }^{\circ} \mathrm{C}$ in the morning up to $28{ }^{\circ} \mathrm{C}$ around noon. There was no carbon dioxide enrichment on this day. Due to ventilation, which varied from 3.5 to $13.2 \mathrm{~h}^{-1}$, the $\mathrm{CO}_{2}$ concentration stayed on a level of about $330 \mathrm{ppm}$. The measured photosynthesis varied between zero (or even negative values) and almost $2 \mathrm{~g} \mathrm{~m}^{-2} \mathrm{~h}^{-1}$.

Fig. 2 shows the data of 2 October. This was a sunny, cloudless day with a maximum radiation intensity around $530 \mathrm{~W} \mathrm{~m}^{-2}$. $\mathrm{CO}_{2}$ was injected until about 500 or 700 ppm, every time the concentration fell below $330 \mathrm{ppm}$. The temperature varied between $20.5^{\circ} \mathrm{C}$ in the morning and almost $28^{\circ} \mathrm{C}$ between 12 and $14 \mathrm{~h}$. The measured and simulated photosynthesis reached peaks of about $3 \mathrm{~g} \mathrm{CO}_{2} \mathrm{~m}^{-2} \mathrm{~h}^{-1}$.

Fig. 3 shows the same data for 20 October, the last day of the experiment. That day it was partly cloudy and the maximum radiation (about $300 \mathrm{~W} \mathrm{~m}^{-2}$ ) occurred around noon. The temperature fluctuated between 20.2 and $24^{\circ} \mathrm{C} . \mathrm{CO}_{2}$ was injected three times on this day, up to $600-700 \mathrm{ppm}$. The peaks in (measured) photosynthesis exceeded $2 \mathrm{~g} \mathrm{CO}_{2} \mathrm{~m}^{-2} \mathrm{~h}^{-1}$.

1 Light transmissivity for direct light was calculated.

2 At $340 \mathrm{ppm} \mathrm{CO}_{2}$ and $25^{\circ} \mathrm{C}$. 

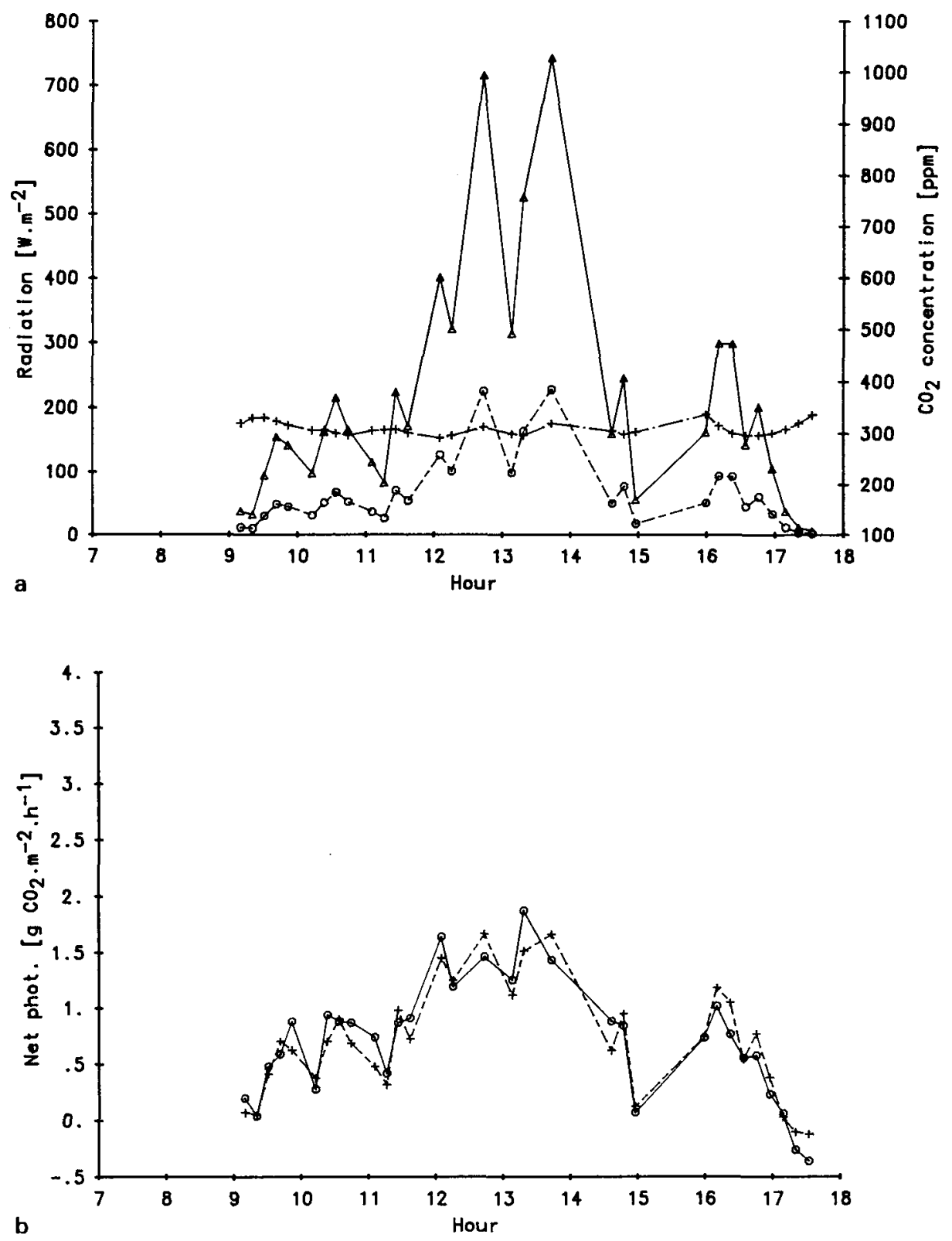

Fig. 1. (a) Main environmental data of 26 August 1987, acquired during photosynthesis measurements: $\triangle-\triangle$ global radiation, measured outside $\left(\mathrm{W} \mathrm{m} \mathrm{m}^{-2}\right) ; 0--\bigcirc$ Photosynthetically Active Radiation, calculated values inside greenhouse $\left(\mathrm{W} \mathrm{m}^{-2}\right) ;+-.++\mathrm{CO}_{2}$ concentration of greenhouse air (ppm). (b) Photosynthesis rates $\left(\mathrm{gCO}_{2} \mathrm{~m}^{-2} \mathrm{~h}^{-1}\right)$ of 26 August 1987, as measured in one greenhouse compartment and simulated with the acquired environmental data and plant parameters: $\bigcirc-O$ measured and..++ simulated photosynthesis. 
CROP PHOTOSYNTHESIS OF CUCUMBER IN GREENHOUSES
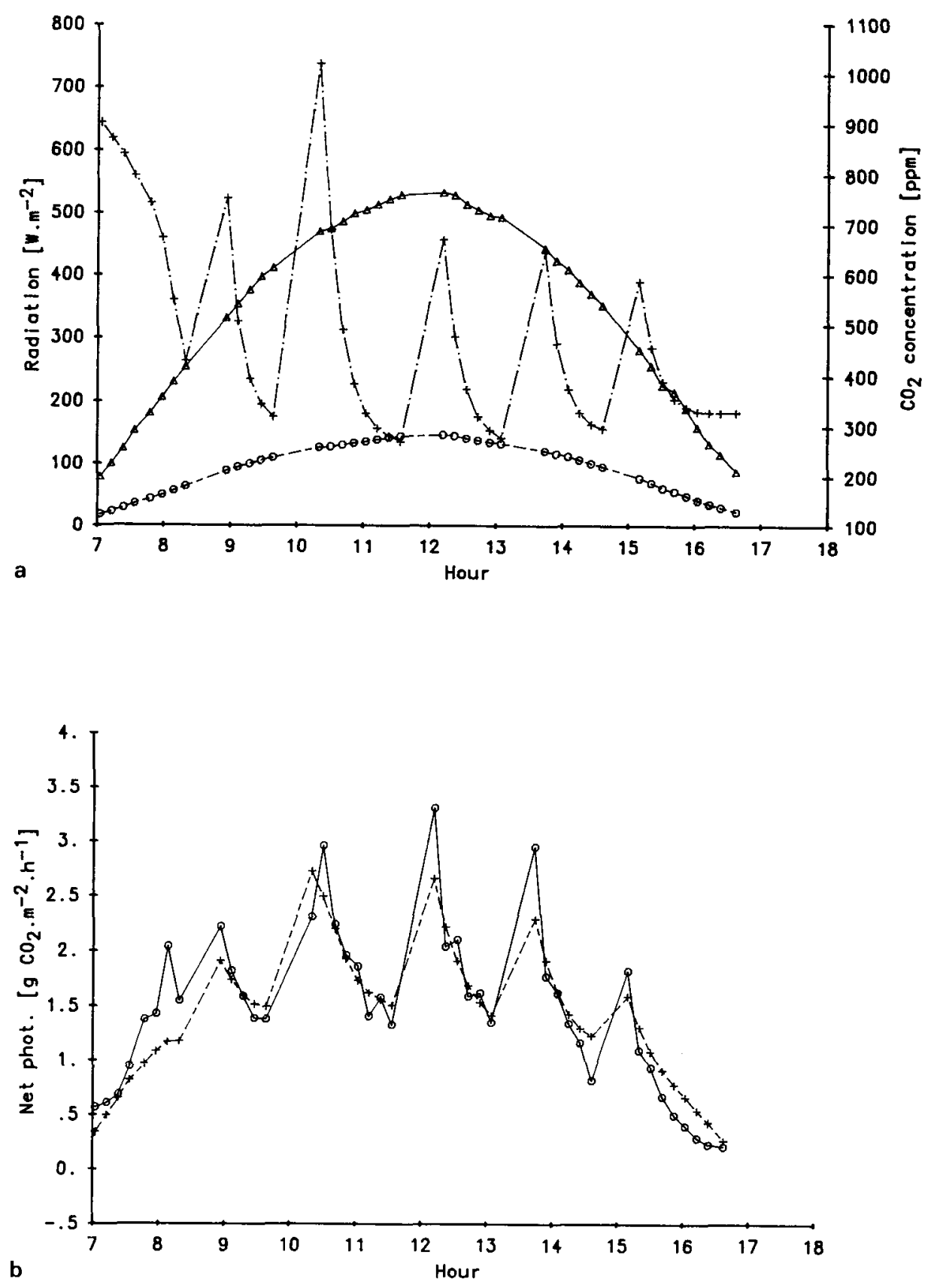

Fig. 2 (a,b). As Fig. 1, data of 2 October 1987. 
E. M. NEDERHOFF J. G. GIJZEN AND J. VEGTER
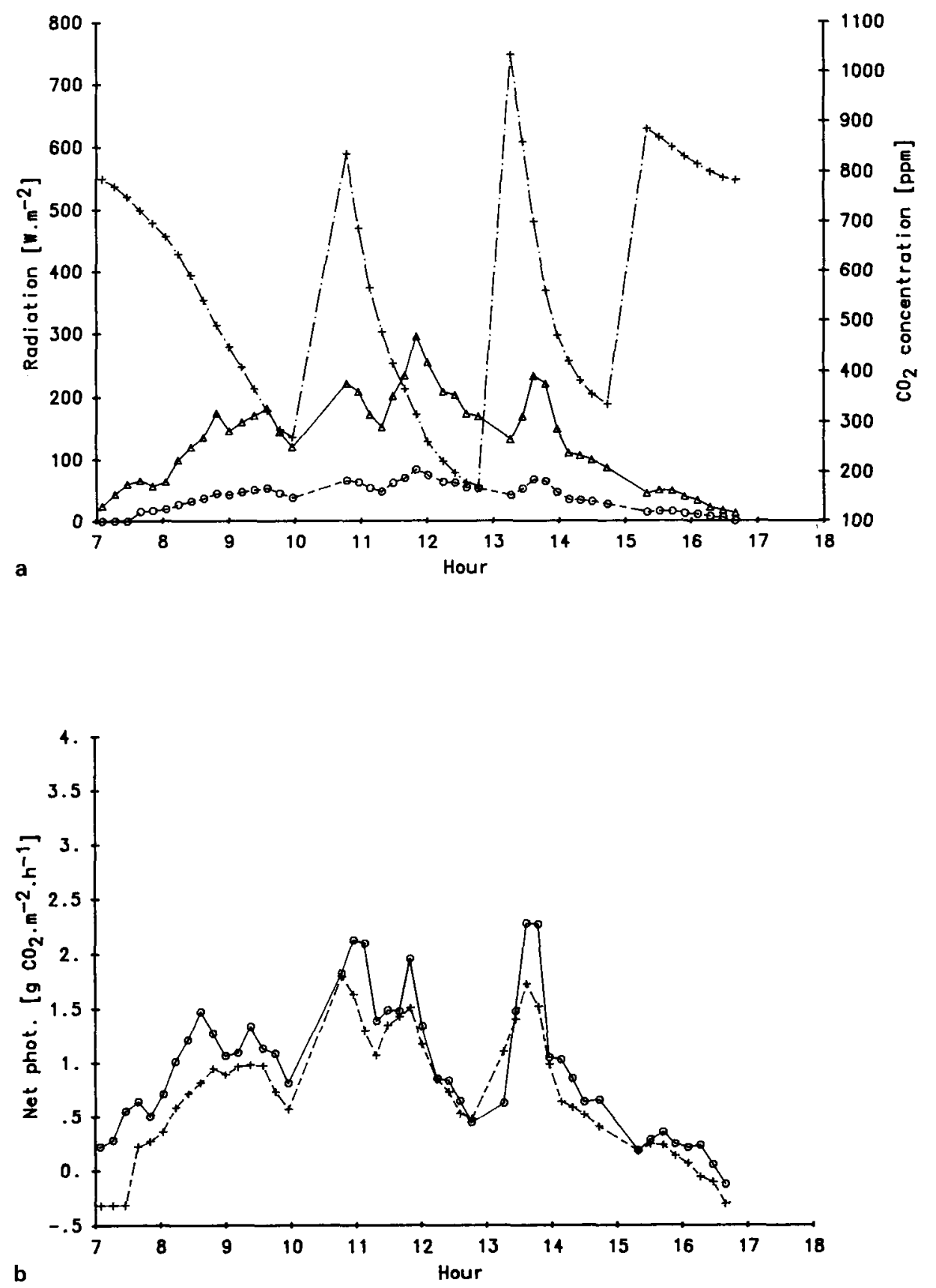

Fig. 3 (a,b). As Fig. 1, data of 20 October 1987. 


\section{Discussion}

In Fig. 1 the results of photosynthesis measurements and simulation are presented for a day with an almost constant $\mathrm{CO}_{2}$ concentration and a varying radiation. The measured photosynthesis roughly follows the radiation curve. The simulated photosynthesis, which is calculated from the measured data of $\mathrm{CO}_{2}$ concentration, radiation and temperature, follows exactly the radiation curve. The simulated values are lower than the measured data, especially around $11.00 \mathrm{~h}$ and at $13.00 \mathrm{~h}$. These discrepancies cannot be explained. Generally, the discrepancies between simulation and measurement are rather small.

In Fig. 2 results are given for a day with an undisturbed radiation curve and varying $\mathrm{CO}_{2}$ concentration. Then the photosynthesis measurements follow roughly the radiation line and exactly the $\mathrm{CO}_{2}$ curve. The pattern in the $\mathrm{CO}_{2}$ concentration with sharp peaks and dips, is found perfectly in the two photosynthesis curves. It is remarkable that at a peak, the discrepancies between measured and simulated photosynthesis are more pronounced. Apparently, after $\mathrm{CO}_{2}$ injection the photosynthesis is underestimated by the model. It seems explicable that the crop reacts strongly on a $\mathrm{CO}_{2}$ injection after a period of $\mathrm{CO}_{2}$ shortage, as sometimes is suggested. This phenomenon is not taken into account in the simulation model, which is based on more or less continuous $\mathrm{CO}_{2}$ concentrations. The measured photosynthesis shortly after a $\mathrm{CO}_{2}$ peak (about 10 minutes later) again shows a good similarity. In general, except for the $\mathrm{CO}_{2}$ peaks, the simulated data of this day are only slightly higher than the measured data.

The lines in Fig. 3, of 20 October, show a capricious pattern both in radiation and $\mathrm{CO}_{2}$ concentration (Fig. 3a). Also the photosynthesis (Fig. 3b) is variable. After $\mathrm{CO}_{2}$ injection peaks (at $10.55 \mathrm{~h}$ and $13.20 \mathrm{~h}$ ) the measured photosynthesis exceeds the simulated photosynthesis, as in Fig. 2b. Again this could be a photosynthesis response to sudden $\mathrm{CO}_{2}$ enrichment, which is not simulated by the model. In general the simulated photosynthesis is only slightly lower than the measured photosynthesis on this day.

The conclusion of these three measurement days is that the simulation corresponds quite well with the measurements. These results illustrate the utility of the simulation model. Only the performance of the model for dynamic conditions (strong elevation of the $\mathrm{CO}_{2}$ concentration after a period of $\mathrm{CO}_{2}$ depletion) causes discrepancies.

In a future publication, the results will be analysed further. Later the model will be improved if necessary and extended for dynamic conditions.

\section{References}

Acock, B., D. A. Charles-Edwards, D. J. Fitter, D. W. Hand, L. J. Ludwig, J. Warren, Wilson \& A. C. Whithers, 1978. The contribution of leaves from different levels within a tomato crop to canopy net photosynthesis: an experimental examination of two canopy models. Journal of Experimental Botany 29: $815-827$.

Bot, G. P. A. 1983. Greenhouse climate: from physical processes to a dynamic model. Doctoral Thesis, Agricultural University, Wageningen, $240 \mathrm{pp}$. 


\section{E. M. NEDERHOFF J. G. GIJZEN AND J. VEGTER}

Challa, H., 1985. Report of the working party 'Crop growth models' Acta Horticulturae 174: 169-175.

Challa, H. \& A. H. C. M. Schapendonk, 1986. Dynamic optimalization of the $\mathrm{CO}_{2}$ concentration in relation to climate control in greenhouses. In: H. Z. Enoch \& B. A. Kimball (Eds.), Carbon dioxide enrichment of greenhouse crops. Vol. I, Status and $\mathrm{CO}_{2}$ sources, p. 147-160. CRC Press Inc., Boca Raton, Florida, USA.

Dayan E., I. Zipori, H. Z. Enoch, D. Schmuel \& P. Gefen, 1985. A system for measuring photosynthesis and respiration rates of crops in commercial size greenhouses. Acta Horticulturae 174: 505-512.

Ehleringer, J. \& R. W. Pearcy, 1983. Variation in quantum yield for $\mathrm{CO}_{2}$ uptake among $\mathrm{C}_{3}$ and $\mathrm{C}_{4}$ plants. Plant Physiology 73: 555-559.

Farquhar, G. D., S. von Caemmerer \& J. A. Berry, 1980. A biochemical model for photosynthetic $\mathrm{CO}_{2}$ assimilation in leaves of $\mathrm{C}_{3}$ species. Planta 149: 78-90.

Gaastra, P., 1959. Photosynthesis of crop plants as influenced by light, carbon dioxide, temperature and stomatal diffusion resistance. Mededelingen Landbouwhogeschool Wageningen No. 59, $68 \mathrm{pp}$.

Gijzen, J. G. \& J. A. ten Cate, 1988. Prediction of the response of greenhouse crop photosynthesis to environmental factors by integration of physical and biochemical models. Acta Horticulturae (in press).

Goedhart, M., E. M. Nederhoff, A. J. Udink ten Cate \& G. P. A. Bot, 1984. Methods and instruments for ventilation rate measurements. Acta Horticulturae 148: 393-400.

Hand, D. W. \& G. E. Bowman, 1969. Carbon dioxide assimilation measurements in a controlled environment glasshouse. Journal of Agricultural Engineering Research 14: 92-99.

Ho, L. C., R. G. Hurd, L. J. Ludwig, A. F. Shaw, J. H. M. Thornley \& A. C. Withers, 1984. Changes of photosynthesis, carbon budget and mineral content during the growth of the first leaf of cucumber. Annals of Botany 54: 87-101.

Lake, J. V., 1966. Measurement and control of the rate of carbon dioxide assimilation by glasshouse crops. Nature 209: 97-98.

Lakso, A. N., J. F. Bierhuizen \& G. F. P. Martakis, 1984. Light responses of photosynthesis and transpiration of two tomato cultivars under ambient and altered $\mathrm{CO}_{2}$ and $\mathrm{O}_{2}$. Scientia Horticulturae 23: 119128.

Matthews, R. B., B. Marshall, R. A. Saffell \& D. Harris, 1987. Computer control of carbon dioxide concentration in experimental glasshouses and its use to estimate net canopy photosynthesis. Agricultural and Forest Meteorology 40: 279-292.

McPherson, H. G., A. E. Green \& P. L. Rollinson, 1983. The measurement, within seconds, of apparent photosynthetic rates, using a portable instrument. Photosynthetica 17: 395-406.

Nederhoff, E. M., 1983. Light interception of a cucumber crop at different stages of growth. Acta Horticulturae 148: 525-534.

Nederhoff, E. M., J. van de Vooren \& A. J. Udink ten Cate, 1985. A practical tracer gas method to determine ventilation in greenhouses. Journal of Agricultural Engineering Research 31: 309-319.

Nederhoff, E. M., 1988. Dynamic optimization of the $\mathrm{CO}_{2}$ concentrations in greenhouses: an experiment with cucumber (Cucumis sativus L.). Acta Horticulturae (in press).

Nilwik, H. J. M. . 1980. Photosynthesis of whole sweet pepper plants. 2. Response to $\mathrm{CO}_{2}$ concentration, irradiance and temperature as influenced by cultivation conditions. Photosynthetica 14:382-391.

Schapendonk, A. H. C. M. \& P. Brouwer, 1985. Environmental effects on photosynthesis, simulated and experimental results from a study on a 'tomato-minicrop'. Acta Horticulturae 174: 269-275.

Spitters, C. J. T., H. van Keulen \& D. W. G. van Kraalingen, 1988. A simple and universal crop growth simulator: SUCROS87. In: R. Rabbinge, S. A. Ward \& H. H. van Laar (Eds), Simulation and systems management in crop protection. Pudoc, Wageningen (in press). 